\title{
REALOCAÇÃO DE NITROGÊNIO E DE BIOMASSA PARA OS GRÃOS, EM TRIGO SUBMETIDO A INOCULAÇÃO DE AZOSPIRILLUM ${ }^{1}$
}

\author{
AGOSTINHO DIRCEU DIDONET ${ }^{2}$, OSVALDO DOS SANTOS LIMA ${ }^{3}$, \\ ANDRÉ ALESSANDRO CANDATEN ${ }^{4}$ e OSMAR RODRIGUES ${ }^{5}$
}

\begin{abstract}
RESUMO - Estudou-se, em condições de campo, o efeito de inoculante turfoso em pó contendo bactérias do gênero Azospirillum no rendimento de grãos e na remobilização de $\mathrm{N}$ e de biomassa para os grãos de trigo (Triticum aestivum L.), cultivar Embrapa 16. Usaram-se como inoculantes, a estirpe de Azospirillum brasilense 245 e o isolado 10 de Azospirillum lipoferum. Em cada tratamento de inoculação, e também sem inoculação, aplicaram-se diferentes doses de $\mathrm{N}$ em diferentes estádios de desenvolvimento das plantas, distribuídos em blocos ao acaso com parcelas subdivididas. Na antese e na maturação fisiológica, avaliaram-se o acúmulo de massa seca e $\mathrm{N}$ total nas diferentes partes da planta. Na colheita, além do rendimento de grãos, avaliaram-se também o índice de colheita para biomassa e para N, os principais componentes do rendimento e o teor de $\mathrm{N}$ total de grãos. Os resultados ainda preliminares evidenciaram que, mesmo não havendo efeito da inoculação no rendimento de grãos, houve um melhor alocamento de $\mathrm{N}$ e de biomassa para os grãos, resultando em maior massa de mil grãos e em menor quantidade de $\mathrm{N}$ restante na palha das plantas na maturação fisiológica. Esses efeitos resultaram de um menor número de espigas $\mathrm{m}^{-2}$, provavelmente devido à morte de afilhos, fator que determinou maior disponibilidade de $\mathrm{N}$ e de biomassa às espigas e grãos restantes.
\end{abstract}

Termos para indexação: inoculação, Azospirillum, Triticum aestivum, translocação de N.

\section{REALLOCATION OF NITROGEN AND BIOMASS TO THE SEEDS IN WHEAT INOCULATED WITH AZOSPIRILLUM BACTERIA}

\begin{abstract}
The effect of inoculating wheat (Triticum aestivum L.) seeds, cultivar Embrapa 16, with powder peat inoculant containing Azospirillum bacteria on yield and remobilization of nitrogen and biomass was studied under field conditions. The strain of Azospirillum brasilense 245 and the isolate 10 of Azospirillum lipoferum were used as inoculants. Different rates of nitrogen were applied at varying stages of plant growth for each inoculated and non-inoculated treatment, distributed in blocks at random with split plots. The accumulation of dry matter and total nitrogen in plant parts was evaluated at anthesis and physiological maturity stages. Harvest index for biomass and N, main yield components, and total $\mathrm{N}$ content in the seeds, in addition to yield, were also evaluated at harvest. The preliminary results showed that, even without inoculation effect on yield, there was a better allocation of nitrogen and biomass to the seeds, resulting in heavier seeds, with a lower amount of nitrogen remaining in the straw at physiological maturity. Such effects resulted from a lower number of spikes $\mathrm{m}^{-2}$, probably due to the death of tillers, determining a greater availability of $\mathrm{N}$ and biomass to the remaining spikes and seeds.
\end{abstract}

Index terms: inoculation, Azospirillum, Triticum aestivum, nitrogen translocation.

\footnotetext{
${ }^{1}$ Aceito para publicação em 23 de março de 1999.

${ }^{2}$ Eng. Agrôn., Dr., Embrapa-Centro Nacional de Pesquisa de

Trigo (CNPT), Caixa Postal 451, CEP 99001-970 Passo Fundo, RS. Bolsista do CNPq. E-mail: didonet@cnpt.embrapa.br

${ }^{3}$ Eng. Agrôn., Rua Moron, 2474, Centro, CEP 99001-970 Passo Fundo, RS. Bolsista do CNPq.

${ }^{4}$ Eng. Agrôn., Rua Fagundes dos Reis, 27, CEP 99001-970 Passo Fundo, RS. Bolsista do CNPq.

${ }^{5}$ Eng. Agrôn., M.Sc., Embrapa-CNPT.
}

\section{INTRODUÇÃO}

Bactérias diazotróficas estão, em geral, amplamente distribuídas nos solos; a prática de inocular qualquer uma dessas bactérias em sementes deve levar em consideração esse fato. Dessa maneira, a inoculação à base de bactérias do gênero Azospirillum somente atingirá seu objetivo se a estirpe usada conseguir competir satisfatoriamente com 
as diazotróficas nativas e com a microflora geral do solo e, além disso, estabelecer-se tanto na rizosfera quanto no interior das raízes (Döbereiner \& Pedrosa, 1987), tão logo ocorra a emergência das plantas.

Alguns mecanismos têm sido propostos para explicar as respostas observadas de diversas espécies de plantas à inoculação de Azospirillum. Entre esses mecanismos o aumento do sistema radicular, estimulado pela presença de bactérias, através da produção de substâncias promotoras do crescimento radicular, pode resultar em maior absorção de minerais e de água (Okon \& Labandera-Gonzalez, 1994). Normalmente, isso resulta em maior produção de biomassa, que, em condições apropriadas pode proporcionar incremento de rendimento (Fallik et al., 1994), além de afetar a partição dessa biomassa (Bashan \& Dubrosvsky, 1996).

A maioria das respostas positivas, em termos de aumento de rendimento de grãos, à inoculação de Azospirillum, são, geralmente, observadas em condições subótimas de fertilizantes, especialmente de nitrogenados, havendo, nesses casos, um uso mais eficiente do fertilizante nitrogenado disponível (Fages, 1994). O efeito de incremento do sistema radicular, que é determinado no início do desenvolvimento da planta logo após o plantio, e a inoculação, propiciam como no caso de milho, um aumento no número de plantas por área e no número de fileiras de grãos por espiga e essas vantagens iniciais podem, ou não, repercutir na colheita, o que dependerá das condições posteriores de desenvolvimento (Fages, 1994). Essas vantagens iniciais das plantas infectadas poderiam ser compensadas pelas plantas não infectadas, uma vez que os demais componentes do rendimento são definidos mais tardiamente. Mesmo não ocorrendo incremento de rendimento, de maneira geral tem havido melhor uso do fertilizante, decorrente do melhor desenvolvimento radicular nos estádios iniciais de crescimento das plantas, proporcionado pelas bactérias.

Em trigo, há algumas indicações de que plantas infectadas tendem a absorver mais $\mathrm{N}$ após a antese, em comparação com plantas não infectadas e adubadas com a mesma quantidade de N (Didonet et al., 1996). Normalmente, a absorção mais tardia de $\mathrm{N}$ pelas plantas de trigo somente incrementa o teor de proteínas nos grãos e raramente promove au- mento de rendimento (Spiertz \& De Vos, 1983). Já o N absorvido na fase inicial do crescimento de plantas promove o afilhamento e maior percentual de sobrevivência desses afilhos (Longnecker et al., 1993). Em geral, o aumento da absorção de minerais e de água, em trigo, e em outros cereais infectados com Azospirillum, tem sido creditado ao efeito hormonal da bactéria na promoção do crescimento radicular (Lin et al., 1983; Kapulnik et al., 1985; Bashan \& Levanony, 1990). Porém, os aumentos de rendimento decorrentes da inoculação de Azospirillum em várias espécies têm sido inconsistentes (Okon \& Labandera-Gonzalez, 1994), em parte devido ao efeito da bactéria, que se restringe às etapas iniciais do desenvolvimento dessas culturas. Alguns trabalhos mostram que podem existir outros mecanismos pelos quais plantas de milho (Salamone et al., 1996) e de trigo (Ferreira et al., 1987) infectadas com Azospirillum, absorvem mais $\mathrm{N}$ do solo, tais como fixação biológica do $\mathrm{N}$ e aumento da atividade da redutase do nitrato nas plantas, respectivamente.

O objetivo deste trabalho foi verificar o efeito da inoculação, em sementes de trigo, da estirpe de Azospirillum brasilense 245, e de um isolado de Azospirillum lipoferum, na eficiência do uso e remobilização do $\mathrm{N}$.

\section{MATERIAL E MÉTODOS}

O ensaio foi instalado no campo, em área experimental da Embrapa-Centro Nacional de Pesquisa de Trigo (CNPT), em Passo Fundo, latitude 28 15'46" S, no inverno de 1996 (semeadura em 24/6/96 e emergência em 7/7/96), em Latossolo Vermelho-Escuro distrófico com as seguintes características: $\mathrm{pH}=5,9 ; \mathrm{Al}^{3+}=0,04$ meq $100 \mathrm{~g}^{-1}$; $\mathrm{Ca}^{2+}+\mathrm{Mg}^{2+}=7,7$ meq $100 \mathrm{~g}^{-1} ; \mathrm{P}=25$ ppm; $\mathrm{K}=121 \mathrm{ppm} \mathrm{e}$ $\mathrm{MO}=3,2 \%$. A adubação PK foi efetuada conforme recomendação da Comissão Sul-Brasileira de Pesquisa de Trigo, usando-se adubo comercial na formulação 0-20-30. O controle de pragas e doenças foi feito preventivamente, e, sempre que necessário, fez-se a irrigação. A inoculação nas sementes da cultivar de trigo Embrapa 16 foi efetuada no momento da semeadura, com inoculante turfoso em pó, da estirpe de Azospirillum brasilense 245 e do isolado número 10 de Azospirillum lipoferum (isolado pela EmbrapaCNPT, a partir de raízes lavadas de trigo da cultivar Embrapa 16), misturando-se $1,8 \mathrm{~g}$ de inoculante com $10^{9}$ células de bactérias $\mathrm{g}^{-1}$ de inoculante turfoso em pó, para cada $150 \mathrm{~g}$ de sementes. Cada parcela era constituída 
de seis linhas de $6,0 \mathrm{~m}$ de comprimento, com espaçamento de $0,20 \mathrm{~m}$, com densidade de 300 plantas aptas $\mathrm{m}^{-2}$. Em cada tratamento referente à inoculação (inoculante turfoso da estirpe 245 , inoculante turfoso do isolado 10) e sem inoculação, foram aplicadas as seguintes doses de $\mathrm{N}$ na forma de uréia, em diferentes estádios de desenvolvimento das plantas, a saber: A) testemunha sem N; B) $15 \mathrm{~kg} \mathrm{ha}^{-1}$ de $\mathrm{N}$ aplicados na semeadura; C) $30 \mathrm{~kg} \mathrm{ha}^{-1}$ de $\mathrm{N}$ aplicados na semeadura; D) $45 \mathrm{~kg} \mathrm{ha}^{-1}$ de $\mathrm{N}$ aplicados na semeadura; E) $45 \mathrm{~kg} \mathrm{ha}^{-1}$ de $\mathrm{N}$ aplicados no afilhamento; F) $15 \mathrm{~kg} \mathrm{ha}^{-1}$ de $\mathrm{N}$ aplicados na semeadura e $45 \mathrm{~kg} \mathrm{ha}^{-1}$ de $\mathrm{N}$ aplicados no afilhamento; G) $15 \mathrm{~kg} \mathrm{ha}^{-1}$ de N aplicados na semeadura e $45 \mathrm{~kg} \mathrm{ha}^{-1}$ de $\mathrm{N}$ aplicados no estádio de duplo anel; H) $45 \mathrm{~kg} \mathrm{ha}^{-1}$ de $\mathrm{N}$ aplicados no estádio de espigueta terminal. Os três tratamentos referentes à inoculação dos dois inoculantes e sem inoculação constituíram as parcelas principais, e os tratamentos relativos às doses de $\mathrm{N}$ (ítens $\mathrm{A}$ até $\mathrm{H}$ ), as subparcelas, sorteados em blocos ao acaso, com quatro repetições. As coletas para avaliação do acúmulo de massa seca e de $\mathrm{N}$-total nas diferentes partes da planta foram efetuadas nos estádios correspondentes à antese (folhas, colmos e espigas) e à maturação fisiológica (folhas, colmos, palha da espiga e grãos), em $0,5 \mathrm{~m}$ linear previamente demarcado, sempre com o mesmo número de plantas. A massa seca foi obtida após secagem do material em estufa ventilada, a $65^{\circ} \mathrm{C}$, por quatro dias. O material, após moído, foi usado para determinação de N-total, pelo método semimicro Kjeldhal. Por ocasião da colheita, foi avaliado o rendimento de grãos a $13 \%$ de umidade e deter- minaram-se os componentes de rendimento, em área útil de $1,2 \mathrm{~m}^{2}$ de cada parcela.

\section{RESULTADOS E DISCUSSÃO}

A acumulação de massa seca verificada na antese e na maturação fisiológica não foi diferenciada em relação aos tratamentos relativos à inoculação e sem inoculação (Tabela 1), porém, na antese, houve interação significativa entre esses e as doses e épocas de aplicação de $\mathrm{N}$ testadas (Tabela 2). Essa interação não foi mais observada na avaliação efetuada na maturação fisiológica (Tabela 3). Ressalta-se que, na antese, os inoculantes da estirpe 245 e do isolado 10 afetaram de forma diferenciada somente a acumulação de massa seca das espigas, e não a de colmos ou folhas, em relação às diferentes doses e épocas de aplicação de N, em comparação com o tratamento sem inoculação. Esses resultados mostram que o acúmulo de biomassa nas espigas da cultivar de trigo Embrapa 16 até a antese foi influenciado pela dose e pela época de aplicação de $\mathrm{N}$ somente quando houve inoculação de ambas as estirpes de Azospirillum testadas, ao contrário do tratamento sem inoculação.

Até a antese, em todas as partes da planta (folhas, colmos e espigas), as maiores respostas em ter-

TABELA 1. Massa seca total acumulada em partes de plantas de trigo, cultivar Embrapa 16, infectadas com a estirpe de Azospirillum brasilense 245 e com o isolado 10 de Azospirillum lipoferum, em condições de campo, determinada na antese e na maturação fisiológica ${ }^{1}$.

\begin{tabular}{lccc}
\hline Parte da planta & & Massa seca $\left(\mathrm{kg} \mathrm{ha}^{-1}\right)$ \\
\cline { 2 - 3 } & Sem inoculação & Inoculante 245 & $\begin{array}{c}\text { Inoculante } \\
\text { Isolado } 10\end{array}$ \\
\hline & & & \\
Folhas & $1455 \mathrm{a}$ & Antese & $1325 \mathrm{a}$ \\
Colmos & $4197 \mathrm{a}$ & $1294 \mathrm{a}$ & $3863 \mathrm{a}$ \\
Espigas & $1291 \mathrm{a}$ & $3914 \mathrm{a}$ & $1176 \mathrm{a}$ \\
\hline Total & $6943 \mathrm{a}$ & $1220 \mathrm{a}$ & $6364 \mathrm{a}$ \\
\hline & & $6428 \mathrm{a}$ & $794 \mathrm{a}$ \\
Folhas & $847 \mathrm{a}$ & Maturação fisiológica & $3943 \mathrm{a}$ \\
Colmos & $4245 \mathrm{a}$ & $784 \mathrm{a}$ & $1433 \mathrm{a}$ \\
Palha da espiga & $1582 \mathrm{a}$ & $3936 \mathrm{a}$ & $3714 \mathrm{a}$ \\
Grãos & $3837 \mathrm{a}$ & $1425 \mathrm{a}$ & $9857 \mathrm{a}$ \\
\hline Total & $10511 \mathrm{a}$ & $3749 \mathrm{a}$ & $9808 \mathrm{a}$ \\
\hline
\end{tabular}

${ }^{1}$ Valores seguidos da mesma letra, em cada linha, não diferem entre si, pelo teste de Duncan, a 5\% de probabilidade. 
mos de acumulação de biomassa resultantes das doses e das épocas de aplicação de $\mathrm{N}$ testadas foram sempre observadas quando houve a inoculação de ambas as estirpes. Esses resultados demonstram que o efeito da inoculação no acúmulo de massa seca das plantas avaliado na antese somente ocorreu em virtude das diferentes doses e épocas de aplicação de $\mathrm{N}$; nas menores doses de $\mathrm{N}$ aplicados na semeadura, a inoculação causou menor acúmulo de massa seca.
O menor acúmulo de massa seca observado quando se aplicaram as menores doses de $\mathrm{N}$, pode ter sido decorrente de um maior investimento das plantas em seu sistema radicular, em detrimento da parte aérea, provocado pela inoculação. Embora esse parâmetro não tenha sido avaliado, vários autores têm observado que plantas infectadas com bactérias do gênero Azospirillum promovem um incremento significativo na biomassa e no volume radicular, principalmente nas etapas iniciais de desenvolvimen-

TABELA 2. Massa seca de folhas, de colmos e de espigas em plantas de trigo, cultivar Embrapa 16, infectada com a estirpe de Azospirillum brasilense 245 e com o isolado 10 de Azospirillum lipoferum em diferentes doses e épocas de aplicação de nitrogênio, em condições de campo, determinada na antese ${ }^{1}$.

\begin{tabular}{|c|c|c|c|}
\hline \multirow[t]{2}{*}{ Tratamento } & \multicolumn{3}{|c|}{ Massa seca $\left(\mathrm{kg} \mathrm{ha}^{-1}\right)$} \\
\hline & Sem inoculação & $\begin{array}{c}\text { Inoculante } \\
245\end{array}$ & $\begin{array}{l}\text { Inoculante } \\
\text { Isolado } 10\end{array}$ \\
\hline & \multicolumn{3}{|c|}{ Folhas } \\
\hline Sem nitrogênio & $1268 \mathrm{bA}$ & $1053 \mathrm{cdA}$ & $969 \mathrm{dA}$ \\
\hline $15 \mathrm{~kg} \mathrm{ha}^{-1}$ de $\mathrm{N}$ aplicados na semeadura & $1485 \mathrm{abA}$ & 1284 abcdA & $1142 \mathrm{cdA}$ \\
\hline $30 \mathrm{~kg} \mathrm{ha}^{-1}$ de $\mathrm{N}$ aplicados na semeadura & $1458 \mathrm{abA}$ & $1012 \mathrm{dA}$ & $1380 \mathrm{abcA}$ \\
\hline $45 \mathrm{~kg} \mathrm{ha}^{-1}$ de $\mathrm{N}$ aplicados na semeadura & $1635 \mathrm{aA}$ & $1149 \mathrm{bcdA}$ & $1090 \mathrm{cdA}$ \\
\hline $45 \mathrm{~kg} \mathrm{ha}^{-1}$ de $\mathrm{N}$ aplicados no afilhamento & $1425 \mathrm{abA}$ & $1586 \mathrm{aA}$ & $1557 \mathrm{abA}$ \\
\hline $15 \mathrm{~kg} \mathrm{ha}^{-1}$ de $\mathrm{N}$ na semeadura $45 \mathrm{~kg} \mathrm{ha}^{-1}$ de $\mathrm{N}$ no afilhamento & $1379 \mathrm{abA}$ & 1365 abcA & $1646 \mathrm{aA}$ \\
\hline $15 \mathrm{~kg} \mathrm{ha}^{-1}$ de $\mathrm{N}$ na semeadura $45 \mathrm{~kg} \mathrm{ha}^{-1}$ de $\mathrm{N}$ no estádio duplo anel & $1645 \mathrm{aA}$ & $1489 \mathrm{aA}$ & $1526 \mathrm{abA}$ \\
\hline $45 \mathrm{~kg} \mathrm{ha}^{-1}$ de $\mathrm{N}$ aplicados no estádio de espigueta terminal & $1351 \mathrm{abA}$ & $1416 \mathrm{abA}$ & $1291 \mathrm{bcdA}$ \\
\hline \multirow[t]{2}{*}{ Média } & $1455 \mathrm{~A}$ & $1294 \mathrm{~A}$ & $1325 \mathrm{~A}$ \\
\hline & \multicolumn{3}{|c|}{ Colmos } \\
\hline Sem nitrogênio & $3703 \mathrm{cA}$ & $3335 \mathrm{bcA}$ & $3071 \mathrm{cA}$ \\
\hline $15 \mathrm{~kg} \mathrm{ha}^{-1}$ de $\mathrm{N}$ aplicados na semeadura & 4332 abcA & $3977 \mathrm{bcA}$ & $3590 \mathrm{bcA}$ \\
\hline $30 \mathrm{~kg} \mathrm{ha}^{-1}$ de $\mathrm{N}$ aplicados na semeadura & 4181 abcA & $3162 \mathrm{cA}$ & $4144 \mathrm{abA}$ \\
\hline $45 \mathrm{~kg} \mathrm{ha}^{-1}$ de $\mathrm{N}$ aplicados na semeadura & $4822 \mathrm{abA}$ & $3658 \mathrm{bcA}$ & $3080 \mathrm{cA}$ \\
\hline $45 \mathrm{~kg} \mathrm{ha}^{-1}$ de $\mathrm{N}$ aplicados no afilhamento & $3841 \mathrm{cA}$ & $5114 \mathrm{aA}$ & $4383 \mathrm{abA}$ \\
\hline $15 \mathrm{~kg} \mathrm{ha}^{-1}$ de $\mathrm{N}$ na semeadura $45 \mathrm{~kg} \mathrm{ha}^{-1}$ de $\mathrm{N}$ no afilhamento & $4106 \mathrm{bc}$ & $3987 \mathrm{bcA}$ & $4851 \mathrm{aA}$ \\
\hline $15 \mathrm{~kg} \mathrm{ha}^{-1}$ de $\mathrm{N}$ na semeadura $45 \mathrm{~kg} \mathrm{ha}^{-1}$ de $\mathrm{N}$ no estádio duplo anel & 5068 aA & $4157 \mathrm{bA}$ & $4305 \mathrm{abA}$ \\
\hline $45 \mathrm{~kg} \mathrm{ha}^{-1}$ de $\mathrm{N}$ aplicados no estádio de espigueta terminal & $3522 \mathrm{cA}$ & 3922 bcA & $3487 \mathrm{bcA}$ \\
\hline \multirow[t]{2}{*}{ Média } & $4197 \mathrm{~A}$ & $3914 \mathrm{~A}$ & $3864 \mathrm{~A}$ \\
\hline & \multicolumn{3}{|c|}{ Espigas } \\
\hline Sem nitrogênio & $1155 \mathrm{aA}$ & $1085 \mathrm{bcA}$ & $917 \mathrm{cA}$ \\
\hline $15 \mathrm{~kg} \mathrm{ha}^{-1}$ de $\mathrm{N}$ aplicados na semeadura & $1348 \mathrm{aA}$ & $1224 \mathrm{bcA}$ & $1075 \mathrm{bcA}$ \\
\hline $30 \mathrm{~kg} \mathrm{ha}^{-1}$ de $\mathrm{N}$ aplicados na semeadura & $1293 \mathrm{aA}$ & $977 \mathrm{cA}$ & $1242 \mathrm{abA}$ \\
\hline $45 \mathrm{~kg} \mathrm{ha}^{-1}$ de $\mathrm{N}$ aplicados na semeadura & $1415 \mathrm{aA}$ & $1074 \mathrm{bcA}$ & $918 \mathrm{cA}$ \\
\hline $45 \mathrm{~kg} \mathrm{ha}^{-1} \mathrm{de} \mathrm{N}$ aplicados no afilhamento & $1260 \mathrm{aA}$ & $1566 \mathrm{aA}$ & $1371 \mathrm{aA}$ \\
\hline $15 \mathrm{~kg} \mathrm{ha}^{-1}$ de $\mathrm{N}$ na semeadura $45 \mathrm{~kg} \mathrm{ha}^{-1}$ de $\mathrm{N}$ no afilhamento & $1255 \mathrm{aA}$ & $1240 \mathrm{bcA}$ & $1448 \mathrm{aA}$ \\
\hline $15 \mathrm{~kg} \mathrm{ha}^{-1}$ de $\mathrm{N}$ na semeadura $45 \mathrm{~kg} \mathrm{ha}^{-1}$ de $\mathrm{N}$ no estádio duplo anel & $1389 \mathrm{aA}$ & $1265 \mathrm{bA}$ & $1248 \mathrm{abA}$ \\
\hline $45 \mathrm{~kg} \mathrm{ha}^{-1}$ de $\mathrm{N}$ aplicados no estádio de espigueta terminal & $1216 \mathrm{aA}$ & $1331 \mathrm{abA}$ & $1187 \mathrm{abcA}$ \\
\hline Média & $1291 \mathrm{~A}$ & $1220 \mathrm{~A}$ & $1175 \mathrm{~A}$ \\
\hline
\end{tabular}


to das plantas (Okon \& Labandera-Gonzalez, 1994). Esse maior investimento em biomassa radicular implica maior consumo de esqueletos de carbono, e, conseqüentemente, envolve maiores taxas respiratórias nas raízes de plantas infectadas, desfavorecendo o crescimento da parte aérea, principalmente em condições favoráveis de crescimento (Boogaard et al., 1996). Sob essas condições, um alto investimento em área foliar e uma alta taxa de assimilação de $\mathrm{CO}_{2}$ e, ainda, uma baixa proporção de biomassa alocada para os tecidos em atividade respiratória, serão vantajosos para o crescimento; porém em condições menos favoráveis, esses fatores podem não ser muito desejáveis. Por exemplo, uma alta proporção de biomassa total em raízes pode não ser desejável, uma vez que as raízes são importantes órgãos consumidores de assimilados (Boogaard et al., 1996). Em trigo, cerca de 10\% a $45 \%$ da biomassa total pode ser encontrada abaixo da superfície do solo, e, dependendo das condições do solo, 20 a $50 \%$ dos assimilados podem ser usados para o crescimento das raízes (Hamblin et al., 1991). Essa interpretação parece ser válida no presente caso, uma vez que a interação entre a inoculação e as doses e épocas de aplicação de $\mathrm{N}$ no acúmulo de massa seca determinada na antese (Tabela 2) não mais foi observada na maturação fisiológica (Tabela 3).

Em relação ao N-total acumulado até a antese, houve interação entre os inoculantes da estirpe 245 e do isolado 10 e sem inoculação, com as doses e épocas de aplicação de $\mathrm{N}$ somente em conseqüência do $\mathrm{N}$ acumulado nos colmos, que respondeu melhor à aplicação de $\mathrm{N}$ em cobertura quando houve inoculação, comparado ao tratamento sem inoculação (Tabela 4).

Somente na maturação fisiológica, e não na antese, verificou-se um efeito significativo no acúmulo de $\mathrm{N}$ nas partes da planta de trigo sob influência direta dos dois inoculantes (Tabela 5). Destaca-se que a menor quantidade de $\mathrm{N}$ restante na palhada (folhas, colmos e palha da espiga) não foi observada no $\mathrm{N}$ acumulado nos grãos, uma vez que tanto a inoculação com os dois inoculantes quanto a não inoculação acumularam estatisticamente a mesma quantidade de N-total nos grãos (Tabela 5).

$\mathrm{Na}$ maturação fisiológica também se verificou efeito significativo das doses e épocas de aplicação de $\mathrm{N}$ na acumulação de N-total na planta, e no geral, doses de $\mathrm{N}$ iguais ou superiores a $30 \mathrm{~kg} \mathrm{ha}^{-1}$ de $\mathrm{N}$ proporcionaram as melhores respostas (Tabela 6). Vale destacar, também, que somente na palha da espiga não houve diferenças significativas no N-total acumulado na maturação fisiológica sob influência das doses e épocas de aplicação de N (Tabela 6).

$\mathrm{O}$ índice de colheita para $\mathrm{N}$ e para biomassa, bem como a massa seca de mil sementes, determinados em plantas submetidas à inoculação de ambas as estirpes de Azospirillum, foram estatisticamente superiores aos das plantas sem inoculação. Somente o

TABELA 3. Massa seca de folhas, de colmos, de folhas, da palha da espiga e de grãos, em plantas de trigo, cultivar Embrapa 16, em diferentes doses e épocas de aplicação de nitrogênio, em condições de campo, determinada na maturação fisiológica ${ }^{1}$.

\begin{tabular}{|c|c|c|c|c|}
\hline \multirow[t]{2}{*}{ Tratamento } & \multicolumn{4}{|c|}{ Massa seca $\left(\mathrm{kg} \mathrm{ha}^{-1}\right)$} \\
\hline & Folhas & Colmos & $\begin{array}{c}\text { Palha da } \\
\text { espiga }\end{array}$ & Grãos \\
\hline Sem nitrogênio & $637 \mathrm{c}$ & $3298 \mathrm{c}$ & $1199 \mathrm{~d}$ & $3487 \mathrm{~d}$ \\
\hline $15 \mathrm{~kg} \mathrm{ha}^{-1}$ de $\mathrm{N}$ aplicados na semeadura & $750 \mathrm{bc}$ & $3757 \mathrm{bc}$ & $1322 \mathrm{~cd}$ & $3591 \mathrm{~cd}$ \\
\hline $30 \mathrm{~kg} \mathrm{ha}^{-1}$ de $\mathrm{N}$ aplicados na semeadura & $791 \mathrm{ab}$ & $3981 \mathrm{ab}$ & $1418 \mathrm{bcd}$ & $3781 \mathrm{bc}$ \\
\hline $45 \mathrm{~kg} \mathrm{ha}^{-1}$ de $\mathrm{N}$ aplicados na semeadura & $842 \mathrm{ab}$ & $4163 \mathrm{ab}$ & $1510 \mathrm{abc}$ & $3803 \mathrm{bc}$ \\
\hline $45 \mathrm{~kg} \mathrm{ha}^{-1}$ de $\mathrm{N}$ aplicados no afilhamento & $825 \mathrm{ab}$ & $4257 \mathrm{ab}$ & $1552 \mathrm{abc}$ & $3841 \mathrm{ab}$ \\
\hline $15 \mathrm{~kg} \mathrm{ha}^{-1}$ de $\mathrm{N}$ na semeadura $45 \mathrm{~kg} \mathrm{ha}^{-1}$ de $\mathrm{N}$ no afilhamento & 889 a & 4499 a & 1662 a & 4053 a \\
\hline $15 \mathrm{~kg} \mathrm{ha}^{-1}$ de $\mathrm{N}$ na semeadura $45 \mathrm{~kg} \mathrm{ha}^{-1}$ de $\mathrm{N}$ no estádio duplo anel & $854 \mathrm{ab}$ & $4232 \mathrm{ab}$ & $1579 \mathrm{ab}$ & $3931 \mathrm{ab}$ \\
\hline $45 \mathrm{~kg} \mathrm{ha}^{-1}$ de $\mathrm{N}$ aplicados no estádio de espigueta terminal & $824 \mathrm{ab}$ & $4144 \mathrm{ab}$ & $1597 \mathrm{ab}$ & $3858 \mathrm{ab}$ \\
\hline
\end{tabular}

${ }^{1}$ Valores seguidos da mesma letra, na mesma coluna, não diferem entre si, pelo teste de Duncan, a 5\% de probabilidade. 
TABELA 4. Nitrogênio-total acumulado nos colmos e na parte aérea das plantas de trigo, cultivar Embrapa 16, infectadas com a estirpe de Azospirillum brasilense 245 e com o isolado 10 de Azospirillum lipoferum, em diferentes doses e épocas de aplicação de nitrogênio, em condições de campo, determinado na antese ${ }^{1}$.

\begin{tabular}{|c|c|c|c|}
\hline \multirow[t]{2}{*}{ Tratamento } & \multicolumn{3}{|c|}{ Nitrogênio total acumulado $\left(\mathrm{kg} \mathrm{ha}^{-1}\right.$ de $\left.\mathrm{N}\right)$} \\
\hline & $\begin{array}{c}\text { Sem } \\
\text { inoculação }\end{array}$ & $\begin{array}{c}\text { Inoculante } \\
245\end{array}$ & $\begin{array}{l}\text { Inoculante } \\
\text { Isolado } 10\end{array}$ \\
\hline & \multicolumn{3}{|c|}{ Colmos } \\
\hline Sem nitrogênio & $42,72 \mathrm{a}$ & $36,00 \mathrm{~cd}$ & 30,09 e \\
\hline $15 \mathrm{~kg} \mathrm{ha}^{-1}$ de $\mathrm{N}$ aplicados na semeadura & $45,04 \mathrm{a}$ & $41,67 \mathrm{bcd}$ & $37,75 \mathrm{cde}$ \\
\hline $30 \mathrm{~kg} \mathrm{ha}^{-1}$ de $\mathrm{N}$ aplicados na semeadura & $44,56 \mathrm{a}$ & $32,42 \mathrm{~d}$ & $46,37 \mathrm{abcd}$ \\
\hline $45 \mathrm{~kg} \mathrm{ha}^{-1}$ de $\mathrm{N}$ aplicados na semeadura & $52,93 \mathrm{a}$ & $37,78 \mathrm{bcd}$ & $35,17 \mathrm{de}$ \\
\hline $45 \mathrm{~kg} \mathrm{ha}^{-1}$ de $\mathrm{N}$ aplicados no afilhamento & $45,73 \mathrm{a}$ & 57,69 a & $50,16 \mathrm{ab}$ \\
\hline $15 \mathrm{~kg} \mathrm{ha}^{-1}$ de $\mathrm{N}$ na semeadura $45 \mathrm{~kg} \mathrm{ha}^{-1}$ de $\mathrm{N}$ no afilhamento & $47,48 \mathrm{a}$ & $47,22 \mathrm{abc}$ & $57,23 \mathrm{a}$ \\
\hline $15 \mathrm{~kg} \mathrm{ha}^{-1}$ de $\mathrm{N}$ na semeadura $45 \mathrm{~kg} \mathrm{ha}^{-1}$ de $\mathrm{N}$ no estádio duplo anel & $51,08 \mathrm{a}$ & $45,73 \mathrm{abc}$ & $48,98 \mathrm{abc}$ \\
\hline $45 \mathrm{~kg} \mathrm{ha}^{-1}$ de $\mathrm{N}$ aplicados no estádio de espigueta terminal & $46,95 \mathrm{a}$ & $49,15 \mathrm{ab}$ & $43,65 \mathrm{bcd}$ \\
\hline \multirow[t]{2}{*}{ Média } & $47,06 \mathrm{~A}$ & $43,45 \mathrm{~A}$ & $43,67 \mathrm{~A}$ \\
\hline & \multicolumn{3}{|c|}{ Parte aérea } \\
\hline Sem nitrogênio & 99,43 a & $84,42 \mathrm{~cd}$ & $72,06 \mathrm{c}$ \\
\hline $15 \mathrm{~kg} \mathrm{ha}^{-1}$ de $\mathrm{N}$ aplicados na semeadura & $114,23 \mathrm{a}$ & $95,37 \mathrm{bcd}$ & $86,94 \mathrm{bc}$ \\
\hline $30 \mathrm{~kg} \mathrm{ha}^{-1}$ de $\mathrm{N}$ aplicados na semeadura & $107,92 \mathrm{a}$ & $70,94 \mathrm{~d}$ & $106,80 \mathrm{ab}$ \\
\hline $45 \mathrm{~kg} \mathrm{ha}^{-1}$ de $\mathrm{N}$ aplicados na semeadura & $117,59 \mathrm{a}$ & $84,88 \mathrm{~cd}$ & $79,95 \mathrm{c}$ \\
\hline $45 \mathrm{~kg} \mathrm{ha}^{-1}$ de $\mathrm{N}$ aplicados no afilhamento & $111,28 \mathrm{a}$ & $124,78 \mathrm{a}$ & $114,41 \mathrm{a}$ \\
\hline $15 \mathrm{~kg} \mathrm{ha}^{-1}$ de $\mathrm{N}$ na semeadura $45 \mathrm{~kg} \mathrm{ha}^{-1}$ de $\mathrm{N}$ no afilhamento & $105,81 \mathrm{a}$ & $106,35 \mathrm{abc}$ & $125,20 \mathrm{a}$ \\
\hline $15 \mathrm{~kg} \mathrm{ha}^{-1}$ de $\mathrm{N}$ na semeadura $45 \mathrm{~kg} \mathrm{ha}^{-1}$ de $\mathrm{N}$ no estádio duplo anel & $119,56 \mathrm{a}$ & $115,04 \mathrm{ab}$ & $113,85 \mathrm{a}$ \\
\hline $45 \mathrm{~kg} \mathrm{ha}^{-1}$ de $\mathrm{N}$ aplicados no estádio de espigueta terminal & $108,54 \mathrm{a}$ & $113,07 \mathrm{ab}$ & $106,02 \mathrm{ab}$ \\
\hline Média & $110,54 \mathrm{~A}$ & $99,35 \mathrm{~A}$ & $100,21 \mathrm{~A}$ \\
\hline
\end{tabular}

${ }^{1}$ Valores seguidos da mesma letra minúscula em cada coluna, e, maiúscula na linha, não diferem sentre si pelo teste de Duncan, a 5\% de probabilidade.

TABELA 5. Nitrogênio-total acumulado em partes de plantas de trigo, cultivar Embrapa 16, infectadas com a estirpe de Azospirillum brasilense 245 e com o isolado 10 de Azospirillum lipoferum, em condições de campo determinado na antese e na maturação fisiológica ${ }^{1}$.

\begin{tabular}{lccc}
\hline Parte da planta & \multicolumn{3}{c}{ Nitrogênio total acumulado $\left(\mathrm{kg} \mathrm{ha}^{-1}\right.$ de N) } \\
\cline { 2 - 4 } & Sem inoculação & Inoculante 245 & Inoculante Isolado 10 \\
\hline & $37,9 \mathrm{a}$ & Antese & $33,9 \mathrm{a}$ \\
Folhas & $47,1 \mathrm{a}$ & $31,1 \mathrm{a}$ & $43,7 \mathrm{a}$ \\
Colmos & $25,6 \mathrm{a}$ & $43,5 \mathrm{a}$ & $23,1 \mathrm{a}$ \\
Espigas & $110,5 \mathrm{a}$ & $24,8 \mathrm{a}$ & $100,6 \mathrm{a}$ \\
\hline Total & & $99,4 \mathrm{a}$ & $9,5 \mathrm{~b}$ \\
& $11,0 \mathrm{a}$ & Maturação fisiológica & $15,1 \mathrm{~b}$ \\
Folhas & $17,4 \mathrm{a}$ & $9,1 \mathrm{~b}$ & $12,8 \mathrm{~b}$ \\
Colmos & $15,2 \mathrm{a}$ & $14,5 \mathrm{~b}$ & $95,9 \mathrm{a}$ \\
Palha da espiga & $96,5 \mathrm{a}$ & $12,3 \mathrm{~b}$ & $133,3 \mathrm{ab}$ \\
Grãos & $140,2 \mathrm{a}$ & $93,3 \mathrm{a}$ & $129,2 \mathrm{~b}$ \\
\hline Total & &
\end{tabular}

${ }^{1}$ Valores seguidos da mesma letra, em cada linha, não diferem entre si, pelo teste de Duncan, a 5\% de probabilidade. 
número de espigas por unidade de área foi maior quando não se inoculou; as demais variáveis não apresentaram diferenças significativas entre os tratamentos com inoculação e sem inoculação (Tabela 7). Esses resultados evidenciam que a inoculação promove o uso mais eficiente do $\mathrm{N}$ disponível, o que é refletido em um maior índice de colheita para $\mathrm{N}$ quando se efetuou a inoculação. Por sua vez, o melhor uso de $\mathrm{N}$ também proporciona melhor aproveitamento da biomassa em benefício dos grãos aumentando o índice de colheita resultando em maior massa de mil grãos (Tabela 7).
Uma vez que não se verificaram diferenças no número de sementes por espiga ou no número de sementes por unidade de área, seria de se esperar um menor rendimento de grãos quando não houve inoculação. Tal efeito não foi observado, possivelmente devido ao fato de que na ausência de inoculação detectou-se um maior número de espigas por unidade de área, o que compensaria os menores índices de colheita e o menor peso de sementes (Tabela 7).

$\mathrm{O}$ índice de colheita para $\mathrm{N}$, calculado como a taxa entre o $\mathrm{N}$ presente nos grãos e o N-total avalia-

TABELA 6. Nitrogênio-total acumulado em partes de plantas de trigo, cultivar Embrapa 16, infectadas com a estirpe de Azospirillum brasilense 245 e com o isolado 10 de Azospirillum lipoferum, em diferentes doses e épocas de aplicação de nitrogênio, em condições de campo, determinado na maturação fisiológica ${ }^{1}$.

\begin{tabular}{|c|c|c|c|c|c|}
\hline \multirow[t]{2}{*}{ Tratamento } & \multicolumn{5}{|c|}{ Nitrogênio total acumulado $\left(\mathrm{kg} \mathrm{ha}^{-1} \mathrm{de} \mathrm{N}\right)$} \\
\hline & Folhas & Colmos & $\begin{array}{c}\text { Palha da } \\
\text { espiga }\end{array}$ & Grãos & Total \\
\hline Sem nitrogênio & $7,48 \mathrm{~d}$ & $11,84 \mathrm{c}$ & $10,39 \mathrm{a}$ & $82,77 \mathrm{~d}$ & $112,48 \mathrm{~d}$ \\
\hline $15 \mathrm{~kg} \mathrm{ha}^{-1}$ de $\mathrm{N}$ aplicados na semeadura & $8,44 \mathrm{~cd}$ & $13,73 \mathrm{bc}$ & $12,09 \mathrm{a}$ & $89,71 \mathrm{~cd}$ & $123,98 \mathrm{c}$ \\
\hline $30 \mathrm{~kg} \mathrm{ha}^{-1}$ de $\mathrm{N}$ aplicados na semeadura & $9,23 \mathrm{bcd}$ & $15,61 \mathrm{ab}$ & $13,09 \mathrm{a}$ & $94,12 \mathrm{bc}$ & $132,06 \mathrm{bc}$ \\
\hline $45 \mathrm{~kg} \mathrm{ha}^{-1}$ de $\mathrm{N}$ aplicados na semeadura & $10,82 \mathrm{ab}$ & $16,13 \mathrm{ab}$ & $14,02 \mathrm{a}$ & $95,31 \mathrm{bc}$ & $136,29 \mathrm{ab}$ \\
\hline $45 \mathrm{~kg} \mathrm{ha}^{-1}$ de $\mathrm{N}$ aplicados no afilhamento & $10,18 \mathrm{abc}$ & $15,62 \mathrm{ab}$ & $14,09 \mathrm{a}$ & $97,36 \mathrm{ab}$ & $137,25 \mathrm{ab}$ \\
\hline $15 \mathrm{~kg} \mathrm{ha}^{-1}$ de $\mathrm{N}$ na semeadura $45 \mathrm{~kg} \mathrm{ha}^{-1}$ de $\mathrm{N}$ no afilhamento & $11,04 \mathrm{ab}$ & $16,99 \mathrm{ab}$ & $15,24 \mathrm{a}$ & $103,70 \mathrm{a}$ & $146,97 \mathrm{a}$ \\
\hline $15 \mathrm{~kg} \mathrm{ha}^{-1}$ de $\mathrm{N}$ na semeadura $45 \mathrm{~kg} \mathrm{ha}^{-1}$ de $\mathrm{N}$ no estádio duplo anel & $10,70 \mathrm{ab}$ & 17,19 a & $14,48 \mathrm{a}$ & $100,41 \mathrm{ab}$ & $142,78 \mathrm{ab}$ \\
\hline $45 \mathrm{~kg} \mathrm{ha}^{-1}$ de $\mathrm{N}$ aplicados no estádio de espigueta terminal & $11,09 \mathrm{a}$ & $18,03 \mathrm{a}$ & $14,32 \mathrm{a}$ & $98,39 \mathrm{ab}$ & $141,84 \mathrm{ab}$ \\
\hline
\end{tabular}

${ }^{1}$ Valores seguidos da mesma letra, em cada coluna, não diferem entre si, pelo teste de Duncan, a 5\% de probabilidade.

TABELA 7. Componentes do rendimento de plantas de trigo, cultivar Embrapa 16, infectadas com a estirpe de Azospirillum brasilense 245 e com o isolado 10 de Azospirillum lipoferum, em condições de campo, determinados na maturação fisiológica ${ }^{1}$.

\begin{tabular}{lrrr}
\hline Componentes do rendimento & Sem inoculação & Inoculante 245 & $\begin{array}{r}\text { Inoculante } \\
\text { Isolado } 10\end{array}$ \\
\hline Índice de colheita (\%) & $36,6 \mathrm{~b}$ & $38,0 \mathrm{a}$ & $37,9 \mathrm{a}$ \\
Índice de colheita para N (\%) & $69,2 \mathrm{~b}$ & $72,5 \mathrm{a}$ & $72,4 \mathrm{a}$ \\
Número de espigas m & & $448,6 \mathrm{~b}$ & $446,8 \mathrm{~b}$ \\
Massa seca de mil sementes (g) $^{-2}$ & $488,6 \mathrm{a}$ & $29,0 \mathrm{a}$ & $28,9 \mathrm{a}$ \\
Sementes m & $27,9 \mathrm{~b}$ & $11.611,0 \mathrm{a}$ & $11.666,0 \mathrm{a}$ \\
Sementes espiga $^{-1}$ & $12.069,0 \mathrm{a}$ & $26,1 \mathrm{a}$ & $26,2 \mathrm{a}$ \\
${\text { Rendimento }\left(\mathrm{kg} \mathrm{ha}^{-1}\right)}$ & $25,0 \mathrm{a}$ & $3.785,0 \mathrm{a}$ & $3.799,0 \mathrm{a}$ \\
\hline
\end{tabular}

${ }^{1}$ Valores seguidos da mestra letra, em cada linha, não diferem entre si, pelo teste de Duncan, a $5 \%$ de probabilidade. 
do na maturação fisiológica é uma medida da eficiência na remobilização do $\mathrm{N}$ presente na planta, para os grãos (Austin et al., 1977; Dhugga \& Waines, 1989; Beninati \& Busch, 1992). Valores de índices de colheita para $\mathrm{N}$ variando de 0,77 a 0,85 e de índice de colheita para biomassa variando de 0,39 a 0,44 , também foram encontrados em estudo efetuado por McKendry et al. (1995), em uma série de cultivares de trigo no Canadá.

$\mathrm{O} \mathrm{N}$ acumulado nos grãos, por sua vez, é dependente da interação de vários fatores complexos, como taxa de assimilação de $\mathrm{N}$, taxa de crescimento em relação à assimilação de $\mathrm{N}$, e partição do $\mathrm{N}$ entre o grão e a palhada na maturação (Cregan \& Van Berkum, 1984). Em geral, a acumulação de $\mathrm{N}$ nos grãos, o índice de colheita, a translocação e o uso de $\mathrm{N}$ estão fortemente associados à produção e à partição de massa seca (McMullan et al., 1988; Clarke et al., 1990).

A importância da translocação de biomassa para os grãos, em trigo, advém do fato de que no mundo todo os aumentos na produtividade de trigo estão normalmente associados com o índice de colheita, uma vez que o aumento na produção de biomassa tem se mostrado desprezível (Loss \& Siddique, 1994). Estes resultados, ainda que preliminares, mostram um efeito direto da inoculação das sementes com ambos os inoculantes testados, tanto no índice de colheita, como na realocação do N para os grãos. Há evidências anteriores indicando que a inoculação promove um acréscimo no teor de $\mathrm{N}$ acumulado nos grãos (Boddey et al., 1986).

A redução do peso dos grãos é tipicamente um efeito de altas temperaturas durante o período de enchimento dos grãos, e ocorre basicamente em razão da redução do período de crescimento de grãos (Stone \& Nicholas, 1995), fator esse bastante comum nas condições de cultivo de trigo no Rio Grande do Sul. O aumento do peso de grãos, normalmente, está associado a uma disponibilidade maior de $\mathrm{N}$ durante o período de enchimento de grãos, enquanto uma maior disponibilidade de $\mathrm{N}$ nas fases iniciais de desenvolvimento da planta promove o afilhamento, o crescimento foliar e o número de espiguetas férteis por espiga (Jenner et al., 1991).

A aplicação de $\mathrm{N}$ nos estádios iniciais de desenvolvimento (semeadura) estimula grandemente o aumento de afilhos, porém nem todos produzirão espigas (Abdin et al., 1996). O número de grãos por unidade de área é uma medida que integra os efeitos do afilhamento, da sobrevivência de afilhos, do número de espiguetas e do número de grãos por espiguetas, e as compensações que ocorrem entre esses componentes dependem basicamente de condições ambientes (Midmore et al., 1984). Dessa maneira, a regulação da absorção de $\mathrm{N}$ pela planta no período de desenvolvimento de grãos é efetuada basicamente pelo número de sementes por espiga e pela capacidade dos grãos em armazenar compostos nitrogenados (Pérez et al., 1989).

A eficiência de translocação de $\mathrm{N}$ é variável dentro da planta, e o colmo principal normalmente apresenta maior eficiência, em comparação com os demais afilhos (Halloran, 1981). Essa realocação de N ocorre durante todo o período de desenvolvimento da planta, inicialmente entre os afilhos e os vários órgãos da planta, e posteriormente há uma predominância da realocação de $\mathrm{N}$ do colmo e de folhas para as espigas (Austin et al., 1977).

A competição por $\mathrm{N}$ entre afilhos, que ocorre especialmente em situação de limitação de $\mathrm{N}$, irá definir a quantidade de afilhos viáveis e, conseqüentemente, o número de espigas por unidade de área, fato esse que ocorrerá no período de desenvolvimento próximo à antese (Rawson \& Donald, 1969; Kirby \& Jones, 1977; Pérez et al., 1983; Davidson \& Chevalier, 1990). É possível, portanto, que o menor número de espigas por unidade de área observado nos tratamentos onde se usou a inoculação se deva a um percentual maior de afilhos inviáveis nesses tratamentos, uma vez que o maior crescimento inicial do sistema radicular promoveria o afilhamento, e posteriormente esses afilhos sofreriam maior competição por $\mathrm{N}$, quando esse elemento poderia tornar-se limitante na fase de definição dos afilhos viáveis. Dessa maneira, os afilhos viáveis poderiam realocar mais $\mathrm{N}$ para si, ou, alternativamente, o $\mathrm{N}$ absorvido após a antese seria direcionado para um menor número de afilhos com espiga, em comparação com a ausência de inoculação. Essa compensação pode ter sido a causa da não-alteração no principal componente do rendimento de grãos em trigo, que é o número de sementes por unidade de área (Slafer \& Andrade, 1989; Slafer \& Rawson, 1994). 
Também, o incremento do sistema radicular das plantas que foram inoculadas pode ter proporcionado maior longevidade aos tecidos verdes da planta, resultando numa atividade fotossintética mais prolongada, que forneceria quantidades maiores de assimilados, tanto para os grãos como para absorver $\mathrm{N}$ por um período de tempo maior do que o requerido por plantas não infectadas. Isso tudo resultaria em grãos mais pesados, em maior translocação de $\mathrm{N}$ e de assimilados para os grãos, e também, em maior acúmulo de proteínas (Terman, 1979; Mou et al., 1994; Schulthess et al., 1997), com o mesmo número de sementes por unidade de área, e conseqüentemente, com idêntico rendimento de grãos.

\section{CONCLUSÕES}

1. A inoculação da estirpe 245 e do isolado 10 proporciona melhor aproveitamento do $\mathrm{N}$ acumulado na biomassa, translocando mais eficientemente o N para os grãos.

2. A inoculação também proporciona translocação mais eficiente da biomassa das plantas para os grãos, produzindo basicamente grãos mais pesados e mais cheios.

3. A quantidade de $\mathrm{N}$ presente na palha das plantas por ocasião da maturação fisiológica é menor nos tratamentos inoculados.

4. Mesmo não ocorrendo diferenças no rendimento de grãos e no acúmulo de biomassa na maturação fisiológica, nem no N-total acumulado nos grãos entre os tratamentos inoculados e não inoculados, há um melhor realocamento do $\mathrm{N}$ presente na biomassa para os grãos nas plantas inoculadas.

5. Esses efeitos, mesmo sendo preliminares, são devidos ao menor número de espigas por unidade de área nas plantas infectadas, que pode ser resultante da morte de afilhos e no conseqüente aumento da disponibilidade de $\mathrm{N}$ e de biomassa às espigas restantes.

\section{REFERÊNCIAS}

ABDIN, M.Z.; BANSAL, K.C.; ABROL, Y.P. Effect of split nitrogen application on growth and yield of wheat ( $T$. aestivum L.) genotypes with different
$\mathrm{N}$-assimilation potential. Journal of Agronomy and Crop Science, v.176, p.83-90, 1996.

AUSTIN, R.B.; FORD, M.A.; EDRICH, J.A.; BLACKWELL, R.D. The nitrogen economy of winter wheat. Journal of Agricultural Science, v.88, p.59-167, 1977.

BASHAN, Y.; DUBROVSKY, J.G. Azospirillum spp. participation in dry matter partitioning in grasses at the whole plant level. Biology and Fertility of Soils, v.23, p.435-440, 1996.

BASHAN, Y.; LEVANONY, H. Current status of Azospirillum as a challenge for agriculture. Canadian Journal of Microbiology, v.36, p.591-608, 1990.

BENINATI, N.F.; BUSCH, R.H. Grain protein inheritance and nitrogen uptake and redistribution in a spring wheat cross. Crop Science, v.32, p. 1471-1475, 1992.

BODDEY, R.M.; BALDANI, V.L.D.; BALDANI, J.I.; DÖBEREINER, J. Effect of inoculation of Azospirillum spp. on nitrogen accumulation by field grown wheat. Plant and Soil, v.95, p.109-121, 1986.

BOOGAARD, R. van den; VENEKLAAS, E.J.; LAMBERS, $\mathrm{H}$. The association of biomass allocation with growth and water use efficiency of two Triticum aestivum cultivars. Australian Journal of Plant Physiology, v.23, p.751-761, 1996.

CLARKE, J.M.; CAMPBELL, C.A.; CUTFORTH, H.W.; DEPAUW, R.M.; WINKLEMAN, G.E. Nitrogen and phosphorus uptake, translocation, and utilization efficiency of wheat in relation to environment and cultivar yield and protein levels. Canadian Journal of Plant Science, v.70, p.965-977, 1990.

CREGAN, P.B.; VAN BERKUM, P. Genetics of nitrogen metabolism and physiological/biochemical selection for increased grain crop productivity. Theoretical and Applied Genetics, v.67, p.97-11, 1984.

DAVIDSON, D.J.; CHEVALIER, P.M. Preanthesis tiller mortality in spring wheat. Crop Science, v.30, p.832-836, 1990.

DHUGGA, K.; WAINES, J.G. Analysis of nitrogen accumulation and use in bread and durum wheat. Crop Science, v.29, p.1232-1239, 1989.

DIDONET, A.D.; RODRIGUES, O.; KENNER, M.H. Acúmulo de nitrogênio e de massa seca em plantas de trigo inoculadas com Azospirillum brasilense. Pesquisa Agropecuária Brasileira, Brasília, v.31, n.9, p.645-651, 1996.

Pesq. agropec. bras., Brasília, v.35, n.2, p.401-411, fev. 2000 
DÖBEREINER, J.; PEDROSA, F.O. Agronomic implications. In: DÖBEREINER, J.; PEDROSA, F.O. (Eds.). Nitrogen-fixing bacteria in nonleguminous crop plants. Madison : Science Tech. Publishers. Berlin : Springer-Verlag, 1987. p.107-113.

FAGES, J. Azospirillum inoculants and field experiments. In: OKON, Y. (Ed.). Azospirillum/plant associations. Boca Raton : CRC, 1994. p.87-109.

FALLIK, E.; SARIG, S.; OKON, Y. Morphology and physiology of plant roots associated with Azospirillum. In: OKON, Y. (Ed.). Azospirillum/ plant associations. Boca Raton : CRC, 1994. p.77-85.

FERREIRA, M.C.B.; FERNANDES, M.S.; DÖBEREINER, J. Role of Azospirillum brasilense nitrate reductase in nitrate assimilation by wheat plants. Biology and Fertility of Soils, v.4, p.4753, 1987.

HALLORAN, G.M. Cultivar differences in nitrogen translocation in wheat. Australian Journal of Agricultural Research, v.32, p.535-544, 1981.

HAMBLIN, A.; TENNANT, D.; PERRY, M.W. The cost of stress: dry matter partitioning changes with seasonal supply of water and nitrogen to dryland wheat. Plant and Soil, v.122, p.47-58, 1991.

JENNER, C.F.; UGALDE, T.D.; ASPINALL, D. The physiology of starch and protein deposition in the endosperm of wheat. Australian Journal of Plant Physiology, v.18, p.211-226, 1991.

KAPULNIK, Y.; GAFNY, R.; OKON, Y. Effect of Azospirillum spp. inoculation on root development and $\mathrm{NO}_{3}$-uptake in wheat (Triticum aestivum, cv. Miriam) in hydroponic systems. Canadian Journal of Botany, v.63, p.627-631, 1985.

KIRBY, E.J.M.; JONES, H.G. The relations between the main shoot and tillers in barley plants. Journal of Agricultural Science, v.88, p.381-389, 1977.

LIN, W.; OKON, Y.; HARDY, R.W.F. Enhanced mineral uptake by Zea mays and Sorghum bicolor roots inoculated with Azospirillum brasilense. Applied and Environmental Microbiology, v.45, p.1775-1779, 1983.

LONGNECKER, N.; KIRBY, E.J.M.; ROBSON, A. Leaf emergence, tiller growth, and apical development of nitrogen-deficient spring wheat. Crop Science, v.33, p.154-160, 1993.
LOSS, S.P.; SIDDIQUE, K.H.M. Morphological and physiological traits associated with wheat yield increases in Mediterranean environments. Advances in Agronomy, v.52, p.229-276, 1994.

McKENDRY, L.A.; McVETTY, P.B.E.; EVANS, L.E. Selection criteria for combining high grain yield and high grain protein concentrations in bread wheat. Crop Science, v.35, p.1597-1602, 1995.

McMULLAN, P.M.; McVETTY, P.B.E.; URQUHART, A.A. Dry matter and nitrogen accumulation and redistribution and their relationship to grain yield and grain protein in wheat. Canadian Journal of Plant Science, v.68, p.311-322, 1988.

MIDMORE, D.J.; CARTWRIGHT, P.M.; FISCHER, R.A. Wheat in tropical environments. II. Crop growth and grain yield. Field Crops Research, v.8, p.207227,1984 .

MOU, B.; KRONSTAD, W.E.; SAULESCU, N.N. Grain filling parameters and protein content in selected winter wheat populations: II. Associations. Crop Science, v.34, p.838-841, 1994.

OKON, Y.; LABANDERA-GONZALEZ, C.A. Agronomic applications of Azospirillum: an evaluation of 20 years worldwide field inoculation. Soil Biology and Biochemistry, v.26, p.1591-1601, 1994.

PÉREZ, P.; MARTINEZ-CARRASCO, R.; MARTINDEL MOLINO, I.M.; ROJO, B.; ULLOA, M. Nitrogen uptake and accumulation in grains of three winter wheat varieties with altered source-sink ratios. Journal of Experimental Botany, v.40, p.707-710, 1989.

PÉREZ, P.; MARTINEZ-CARRASCO, R.; PUENTE, L. S. de la. Uptake and distribution of nitrogen in wheat plants supplied with different amounts of nitrogen after stem elongation. Annals of Applied Biology, v.102, p.399-406, 1983.

RAWSON, H.M.; DONALD, C.M. The absorption and distribution of nitrogen after floret initiation in wheat. Australian Journal of Agricultural Research, v.20, p.799-808, 1969.

SALAMONE, I.E.G.; DÖBEREINER, J.; URQUIAGA, S.; BODDEY, R.M. Biological nitrogen fixation in Azospirillum strain-maize genotype associations as evaluated by the ${ }^{15} \mathrm{~N}$ isotope dilution technique. Biology and Fertility of Soils, v.23, p.249-256, 1996. 
SCHULTHESS, U.; FEIL, B.; JUTZI, S.C. Yieldindependent variation in grain nitrogen and phosphorus concentration among Ethiopian wheats. Agronomy Journal, v.89, p.497-506, 1997.

SLAFER, G.A.; ANDRADE, F.H. Genetic improvement in bread wheat (Triticum aestivum) yield in Argentina. Field Crops Research, v.21, p.289-296, 1989.

SLAFER, G.A.; RAWSON, H.M. Sensitivity of wheat phasic development to major environmental factors: A re-examination of some assumptions made by physiologists and modellers. Australian Journal of Plant Physiology, v.21, p.393-426, 1994.
SPIERTZ, J.H.J.; DE VOS, N.M. Agronomical and physiological aspects of the role of nitrogen in yield formation in cereals. Plant and Soil, v.75, p.379$391,1983$.

STONE, P.J.; NICHOLAS, M.E. Effect of timing of heat stress during grain filling on two wheat varieties differing in heat tolerance. I. Grain growth. Australian Journal of Plant Physiology, v.22, p.927-934, 1995.

TERMAN, G.L. Yield and protein content of wheat grain as affected by cultivar, $\mathrm{N}$, and environmental growth factors. Agronomy Journal, v.71, p.437-440, 1979. 